\title{
Two Signaling Pathways Regulate the Expression and Secretion of a Neuropeptide Required for Long-Term Facilitation in Aplysia
}

\author{
Jiang-Yuan Hu, Fang Wu, and Samuel Schacher \\ Center for Neurobiology and Behavior, Columbia University College of Physicians and Surgeons, New York State Psychiatric Institute, New York, New York \\ 10032
}

\begin{abstract}
Activation of several signaling pathways contributes to long-term synaptic plasticity, but how brief stimuli produce coordinated activation of these pathways is not understood. In Aplysia, the long-term facilitation (LTF) of sensory neuron synapses by 5-hydroxytryptamine (serotonin; 5-HT) requires the activation of several kinases, including mitogen-activated protein kinase (MAPK). The 5-HT-enhanced secretion of the sensory neuron-specific neuropeptide sensorin mediates the activation of MAPK. We find that stimulus-induced activation of two signaling pathways, phosphoinositide 3-kinase (PI3K) and type II protein kinase A (PKA), regulate sensorin secretion and responses. Treatment with 5-HT produces a rapid increase in sensorin synthesis, especially at varicosities, which precedes the secretion of sensorin. PI3K inhibitor and rapamycin block LTF and the rapid synthesis of sensorin at varicosities even in the absence of sensory neuron cell bodies. Secretion of the newly synthesized sensorin from the varicosities and activation of the autocrine responses of sensorin to produce LTF require type II PKA interaction with AKAPs (A-kinase anchoring proteins). Thus, long-term synaptic plasticity is produced when multiple signaling pathways that are important for regulating distinct cellular functions are activated in a specific sequence and recruit the secretion of a neuropeptide to activate additional critical pathways.
\end{abstract}

Key words: sensorin; PI3K; type II PKA; MAPK; long-term synaptic plasticity; learning and memory; cell culture

\section{Introduction}

Activation of several signaling pathways contributes to initiating and maintaining long-term synaptic plasticity. Some forms of long-term potentiation (LTP) are initiated by calcium entry to activate calcium/calmodulin kinase II (CaMKII) (Lynch et al., 1983; Bliss and Collingridge, 1993; Miller et al., 2002). Other signaling pathways also are required: protein kinase A (PKA) (Huang et al., 2000; Schafe and LeDoux, 2000; Nguyen and Woo, 2003), protein kinase C (PKC) (Lovinger and Routtenberg, 1988; Malinow et al., 1988; Sacktor et al., 1993; Ling et al., 2002), mitogen-activated protein kinase (MAPK) (Sweatt, 2004), phosphoinositide 3-kinase (PI3K) (Lin et al., 2001; Man et al., 2003; Opazo et al., 2003), and phospholipase C (Minichiello et al., 2002).

How does the relatively brief stimulus that initiates longlasting plasticity activate many signaling pathways? Calcium entry or release from internal stores can activate a number of kinases and phosphatases (Frey et al., 1993; Lisman et al., 2002;

\footnotetext{
Received 0ct. 6, 2005; revised Dec. 5, 2005; accepted Dec. 7, 2005.

This research was supported by National Institutes of Health (NIH) Grants MH 60387 and NS 42159. Animals were provided by the National Center for Research Resources for Aplysia, which is supported by NIH Grant RR-10294, at the University of Florida (Miami, FL). We thank Drs. Jinming Liu and James Schwartz for their technical advice and their comments on previous drafts of this manuscript.

Correspondence should be addressed to Dr. Samuel Schacher, Center for Neurobiology and Behavior, Columbia University College of Physicians and Surgeons, New York State Psychiatric Institute, 1051 Riverside Drive, New York, NY 10032. E-mail: sms2@columbia.edu.

DOI:10.1523/JNEUROSCI.4258-05.2006

Copyright $\odot 2006$ Society for Neuroscience $\quad 0270-6474 / 06 / 261026-10 \$ 15.00 / 0$
}

Malenka and Bear, 2004). Cross talk between signaling pathways also may recruit or inhibit specific signaling pathways (Impey et al., 1998; Roberson et al., 1999; Yamamoto et al., 1999; Waltereit and Weller, 2003). Certain stimuli also lead to the enhanced secretion of neurotrophins, which contribute to some long-lasting forms of hippocampal LTP after binding Trk (tyrosine receptor kinase) receptors, leading to the activation of MAPK and other kinases (Kang et al., 1997; Patterson et al., 2001; Balkowiec and Katz, 2002; Gartner and Staiger, 2002; Minichiello et al., 2002). How is the temporal sequence of kinase activation coordinated, and is that coordinated sequence critical for long-term plasticity?

In Aplysia, several signaling pathways contribute to long-term facilitation (LTF) at sensory neuron synapses produced by 5-hydroxytryptamine (serotonin; 5-HT) or sensitizing stimuli: type I and type II PKA (Greenberg et al., 1987; Liu et al., 2004), p42/44 MAPK (Martin et al.; 1997; Purcell et al., 2003; Hu et al., 2004a), and PI3K (Udo et al., 2005). Some kinases phosphorylate transcription factors and cytoplasmic substrates to regulate macromolecular synthesis (Bartsch et al., 1995, 1998; Chain et al., 1999; Yamamoto et al., 1999; Giustetto et al., 2003; Liu and Schwartz, 2003). Other kinases phosphorylate local substrates that may be critical for regulating synaptic transmission, local protein synthesis, and synaptic growth (Bailey et al., 1992, 1997; Casadio et al., 1999; Angers et al., 2002; Si et al., 2003; Liu et al., 2004; Grabham et al., 2005; Udo et al., 2005). Type II PKA, which is concentrated at synaptic sites, is activated by $5-\mathrm{HT}$, and its increased expression and its interaction with anchoring proteins 
that maintain its proximity to substrates near the membrane are required for LTF (Liu et al., 2004). The activation/translocation of p42/44 MAPK in sensory neurons by 5-HT is mediated by the secretion of the sensory neuron-specific neuropeptide sensorin and activation of autoreceptors (Hu et al., 2004a). How does 5-HT affect sensorin secretion and the responses required for LTF?

We report here that the sequential activation of PI3K and type II PKA mediates enhanced sensorin secretion and its activation/ translocation of MAPK in sensory neurons. Activation of the PI3K pathway enhances sensorin synthesis, especially at varicosities, whereas activation of type II PKA increases secretion of the newly synthesized sensorin from varicosities and enhances the responses of sensorin that lead to LTF. Thus, the sequential activation of two kinases with relatively brief stimuli not only regulates specific functions but also regulates the timely secretion of a neuropeptide that activates additional kinases required for longterm plasticity.

\section{Materials and Methods}

Cell culture and electrophysiology. Sensory neurons were isolated from pleural ganglia dissected from adult animals $(60-80 \mathrm{~g})$, and L7s were isolated from juvenile abdominal ganglia $(2 \mathrm{~g})$ and maintained in coculture for $5 \mathrm{~d}$ (Montarolo et al., 1986). Standard electrophysiological techniques were used to record EPSP amplitudes evoked in L7 ( $\mathrm{Hu}$ et al., 2004). L7s were held at $-85 \mathrm{mV}$. EPSP amplitudes were recorded before and $24 \mathrm{~h}$ after various treatments. Changes in EPSP amplitudes were measured by dividing the post-treatment EPSP amplitude by the pretreatment EPSP amplitude times $100 \%$. No change in amplitude is represented as $100 \%$. LTF was produced by $5 \times 5-\mathrm{HT}$ ( 5 min each at a final concentration of $5 \mu \mathrm{M}$ ) applied at $20 \mathrm{~min}$ intervals. Cultures were rinsed after each application with $10 \mathrm{ml}$ of a 1:1 mixture of L15 medium and seawater. The entire protocol for producing LTF lasted $\sim 90 \mathrm{~min}$. LTF also was produced as described previously (Hu et al., 2004a) with a single application of 5-HT ( $5 \mathrm{~min}$ ), a rapid rinse with L15-sea water medium (10 $\mathrm{ml}$ in $90 \mathrm{~s})$, followed immediately by a $2 \mathrm{~h}$ incubation with sensorin $\mathrm{B}$ neuropeptide $(100 \mathrm{ng} / \mathrm{ml})$.

Drug treatments. Cultures were incubated for $2 \mathrm{~h}$ with anti-sensorin antibody $(\mathrm{Ab})$ or with protein A-purified preimmune serum $(400 \mathrm{ng} / \mathrm{ml})$ (Hu et al., 2004a), starting either immediately after the last application of 5 -HT or $3 \mathrm{~h}$ later. Protein synthesis inhibitor rapamycin (50 nM; Sigma, St. Louis, MO), PI3K inhibitor 2-(4-morpholinyl)-8-phenyl-4H-1benzopyran-4-one (LY294002; $10 \mu \mathrm{M}$; Calbiochem, La Jolla, CA), or PKA inhibitor $(9 R, 10 S, 12 S)-2,3,9,10,11,12$-hexahydro-10-hydroxy-9methyl-1-oxo-9, 12-epoxy-1H-diindolo[1,2,3-fg-3', $2^{\prime}, 1^{\prime}$-K1]pyrrolo [3,4-1][1,6]benzodiazocine-10-carboxylic acid (KT5720; $10 \mu \mathrm{M}$; Calbiochem) was added to cultures $15 \mathrm{~min}$ before $5 \times 5$-HT until immediately after the last application. In some cultures, LY294002 was applied for $2 \mathrm{~h}$ immediately after the last application of 5-HT. The permeable peptide inhibitor of type II PKA interaction with A-kinase anchoring proteins (AKAPs) S-Ht31 (10 $\mu \mathrm{M}$; Promega, Madison, WI) or the mutated control peptide S-Ht31P (10 $\mu \mathrm{M}$; Promega) was added for $2 \mathrm{~h}$ immediately after the last application of 5-HT. For experiments examining the distribution of phosphorylated MAPK, the inhibitor or control peptide was added for only $1 \mathrm{~h}$ immediately after 5-HT.

Immunocytochemistry. Immunocytochemistry was used to monitor expression or changes in the distribution of sensorin or phosphorylated p42/44 MAPK (Hu et al., 2004a). Cultures at various times after 5-HT or after the application of control solutions were rinsed briefly in artificial seawater and fixed in $4 \%$ paraformaldehyde and processed as described previously (Liu et al., 2003; Hu et al., 2004a). Cells were exposed to rabbit polyclonal antibody specific for sensorin (1:1000) or phospho-p42/44 MAPK (1:200; Cell Signaling Technology, Beverly, MA) diluted in 2\% normal goat serum in $0.01 \mathrm{M}$ PBS with $0.3 \%$ Triton X-100 at $4^{\circ} \mathrm{C}$ for $24 \mathrm{~h}$. The incubated cultures were washed in $0.01 \mathrm{M}$ PBS and incubated in FITC-conjugated goat anti-rabbit IgG (1:200; Sigma) at $4^{\circ} \mathrm{C}$ for $4 \mathrm{~h}$. After being washed in $0.01 \mathrm{M}$ PBS, the cultures were imaged directly with a filter set used for detecting fluorescent signal. The cultures were viewed with a
Nikon (Tokyo, Japan) Diaphot microscope attached to a siliconintensified target (SIT; Dage 68; Dage-MTI, Michigan City, MI) video camera, the images were processed by a Dell computer, and the images were captured and processed by the Microcomputer-Controlled Imaging Device (MCID) software package (Imaging Research, St. Catharines, Ontario, Canada). Illumination for detecting fluorescent signals was maintained at a constant setting for all experiments.

In situ hybridization. The specific antisense oligonucleotide probe for sensorin was designed for the specific coding portions of the target sequence used successfully in reverse transcription-PCR analyses of the mRNAs (Schacher et al., 1999) [for probe sequence, see Hu et al. (2002, 2003, 2004b)], synthesized (Genset, La Jolla, CA), lyophilized, and dissolved in sterile distilled water. The sense probe also was designed for use as nonspecific controls. These probes were labeled at the $3^{\prime}$ end with biotin-ddUTP according to the instructions of the manufacturer (Roche Diagnostics, Indianapolis, IN). In situ hybridization was performed as described previously (Hu et al., 2002, 2003). Fixed cultures were hybridized overnight at $42^{\circ} \mathrm{C}$ in hybridization buffer containing $1.5 \mu \mathrm{g} / \mathrm{ml}$ of the biotin-labeled oligonucleotide probes. Unbound probe was washed out. Cultures then were incubated in streptavidin-FITC (1:200; Invitrogen, Gaithersburg, MD) for $4 \mathrm{~h}$ at $4^{\circ} \mathrm{C}$. After unbound streptavidin-FITC was washed out, the hybridization signals were visualized directly with fluorescent microscopy with the imaging system described above. The specificity of biotin-labeled antisense oligonucleotide probe was examined by hybridizing with labeled sense probe or excess unlabeled probe or by omitting probe in hybridization solution as well as RNase pretreatment. All controls were negative. Cells were hybridized under the same conditions to reduce variability.

Quantification and data analysis. All data are expressed as the mean change (percentage) \pm SEM produced by the indicated treatments. The intensity of sensorin immunostaining was tested by measuring average fluorescent intensity in the sensory neuron cell body, the entire main axon, and varicosities contacting the major processes of L7 with the MCID (7.0) software package from Imaging Research. The hybridization signal of sensorin mRNA was measured by averaging fluorescent intensity over the entire sensory cell body. Staining intensity for sensorin mRNA or protein for the various experimental treatments was compared with control treatments that were normalized to $100 \%$. The overall staining intensity of phosphorylated MAPK immunofluorescence was determined by averaging intensity for the cell body (cytoplasm plus nucleus). Nuclear staining was determined by measuring average intensity over that area. ANOVA and Scheffé's $F$ test were used to gauge significant differences between treatments.

\section{Results \\ 5-HT induces the rapid increase in sensorin protein expression that is critical for LTF}

New macromolecular synthesis is required for LTF (Montarolo et al., 1986). Because sensorin secretion is enhanced significantly immediately after five applications of 5-HT $(5 \times 5-\mathrm{HT})$ (Hu et al., $2004 \mathrm{a}$ ), we tested whether $5 \times 5$-HT produces a rapid change in the expression of sensorin protein and mRNA that contributes to the sensorin that is secreted after 5-HT.

Expression of sensorin throughout the sensory neuron was enhanced significantly immediately after the last application of 5-HT ( $0 \mathrm{~h}$ ) (Fig. 1 $A, B)$. Increased staining in distal processes was concentrated primarily in punctate granules along the axon or in varicosities. Compared with controls ( $n=5$ cultures; staining intensity in each compartment normalized to $100 \%)$, 5-HT increased sensorin staining at $0 \mathrm{~h}(n=7$ cultures) in the cell body by nearly twofold (195 $\pm 8 \%$ ), in the axon by nearly fivefold ( $483 \pm$ $25 \%$ ), and in the distal varicosities by more than threefold (307 \pm $9 \%$ ). Then, $2 \mathrm{~h}$ later ( $n=6$ cultures) sensorin expression in axons and varicosities returned to or below baseline. Staining in the axons was only $112 \pm 10 \%$, and staining in varicosities was reduced below control levels to $64 \pm 5 \%$. This rapid decrease in staining was consistent with previous results [Hu et al. (2004a), 
their Fig. 2] and indicated that newly expressed sensorin was secreted from distal processes during the $2 \mathrm{~h}$ period after 5-HT.

The secretion of sensorin during this $2 \mathrm{~h}$ period was critical for LTF. We found previously that exogenous anti-sensorin $\mathrm{Ab}$ binds to and inactivates sensorin ( $\mathrm{Hu}$ et al., 2004a). The antibody blocked LTF when it was applied after 5-HT for $22 \mathrm{~h}$. Incubation with anti-sensorin $\mathrm{Ab}$ for only $2 \mathrm{~h}(0-2 \mathrm{~h}$ after 5 -HT) was sufficient to block LTF, whereas incubation with antisensorin $\mathrm{Ab}$ for $2 \mathrm{~h}$ at a later time (3-5 h after 5-HT) did not block LTF (Fig. 1C). Incubation with anti-sensorin $\mathrm{Ab}$ between 0 and $2 \mathrm{~h}$ ( $n=11$ cultures) reduced the change in EPSP amplitude produced by 5-HT to $103.6 \pm 3.3 \%$ compared with an increase of $154.7 \pm 6.2 \%$ after a $2 \mathrm{~h}$ incubation with control rabbit IgG $(n=9)$. In contrast, EPSP amplitudes increased by $146.6 \pm 6.3 \%$ ( $n=13$ cultures $)$ when cultures were incubated with anti-sensorin $\mathrm{Ab}$ for $2 \mathrm{~h}$ beginning at $3 \mathrm{~h}$ after $5-\mathrm{HT}$. Thus, newly expressed sensorin secreted from the distal processes of sensory neurons immediately after 5 -HT is critical for LTF.

The rapid increase in sensorin protein immediately after 5-HT was not correlated with a rapid increase in sensorin mRNA (Fig. 1D). Compared with controls ( $n=5$ cultures; staining intensity normalized to $100 \%$ for controls), hybridization staining for sensorin mRNA immediately after 5 -HT ( 0 h; $n=5$ cultures) was not significantly different (103 $\pm 8 \%)$. At $2 \mathrm{~h}$ after the treatment with 5-HT ( $n=$ 5 cultures), when sensorin was secreted to deplete the protein from axons and varicosities, staining for sensorin mRNA increased to $133 \pm 12 \%$ above controls. By $12 \mathrm{~h}$ after 5-HT, the staining for both sensorin protein ( $n=6$ cultures) and mRNA ( $n=5$ cultures) was elevated significantly above controls: nearly twofold greater for protein and mRNA in the cell body and nearly threefold greater for sensorin protein in axons and varicosities (Fig. $1 A, B, D)$. Thus, 5 -HT produced two periods of increased sensorin protein synthesis that are likely to be mediated by different mechanisms: a rapid transcription-independent increase that contributed to the sensorin secreted from distal sites immediately after 5-HT and a second phase of increased synthesis known to persist up to $24 \mathrm{~h}$ after 5-HT (Santarelli et al., 1996; Liu et al., 2003) that was preceded by an increase in sensorin mRNA.

\section{$\mathrm{PI} 3 \mathrm{~K}$ and rapamycin regulate the rapid increase in sensorin expression by 5 -HT}

How does 5-HT regulate the rapid synthesis of sensorin? Several kinase activities are activated by 5 -HT. Recent evidence suggests Scale bar, $30 \mu \mathrm{m}$.
A Cont
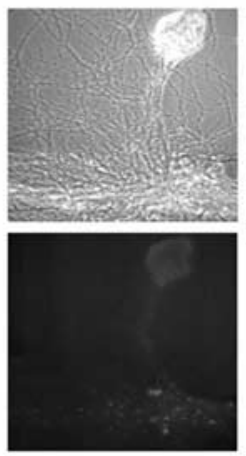

B

$\mathrm{D}$

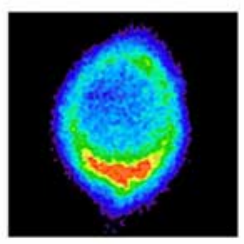

$\mathbf{0 ~ h}$
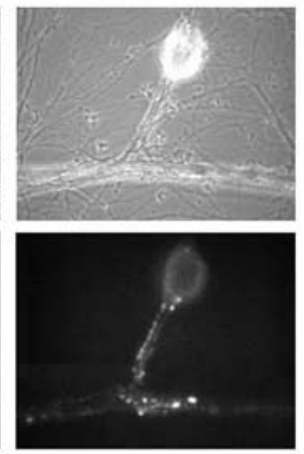

$-\mathrm{cour}$ $0 \mathrm{~h}$
$02 \mathrm{~h}$
$\infty$
$\infty$
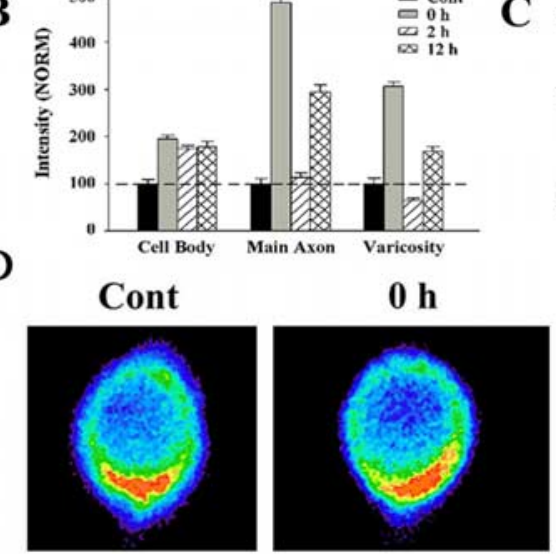

2 h
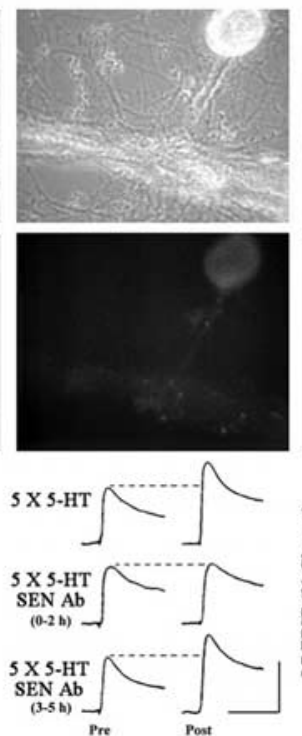

2 h

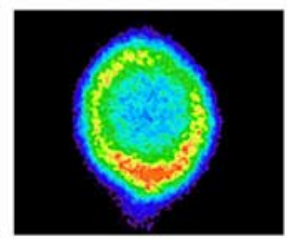

SEN Ab
$12 \mathrm{~h}$
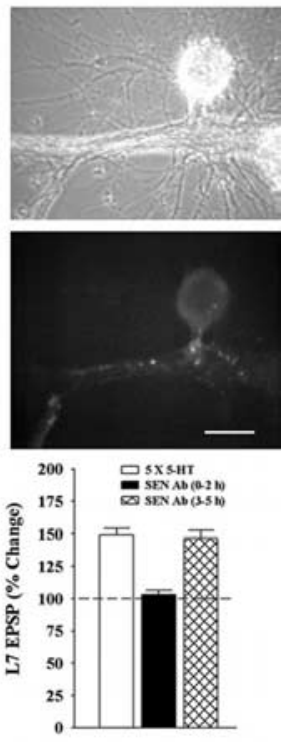

$12 \mathrm{~h}$

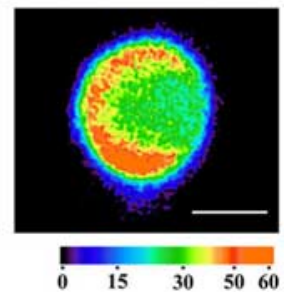

Figure 1. 5 -HT produces a rapid increase in sensorin, the release of which is critical for LTF. A, Nomarski contrast (top) and sensorin immunofluorescent (bottom) images of cocultures after mock applications (Cont) or at various times after $5-\mathrm{HT}$ ( $0 \mathrm{~h}$ is immediately after the last 5 -HT application). Staining in the sensory neuron axon is confined to large granules after treatment and each compartment at 0,2 , and $12 \mathrm{~h}$ after 5 -HT was normalized to the average staining for that compartment in control (dashed line t 100\%). ANOVA indicated a significant effect of treatment ( $\mathrm{df}=6,38 ; F=48.276 ; p<0.001)$. At each time point $(0,2$, and there was an approximately twofold increase in staining in the cell body $(F=19.538$ and $p<0.01 ; F=11.077$ and $p<$ $0.01 ; F=11.169$ and $p<0.01$, respectively). Staining in the axon and at distal varicosities increased significantly at $0 \mathrm{~h}(F=$ 81.211 and $p<0.01 ; F=92.067$ and $p<0.01$, respectively) and then reversed to control levels or below by $2 \mathrm{~h}$ (both were not $p<0.01 ; F=8.908$ and $p<0.01$, respectively). C, Sensorin released between 0 and $2 \mathrm{~h}$ is critical for LTF. EPSPs were recorded before and $24 \mathrm{~h}$ after 5 -HT. Cultures were incubated with anti-sensorin $\mathrm{Ab}(\mathrm{SEN} \mathrm{Ab})$ for $2 \mathrm{~h}$ either immediately after $5-\mathrm{HT}(0-2)$ or $-2 \mathrm{~h}$ blocked LTF but failed to block LTF when applied between 3 and $5 \mathrm{~h}$ after $5-\mathrm{HT}$ ( $F=19.393$ and $p<0.01$ compared with alone; $F=16.57$ and $p<0.01$ when Anti-sensorin Ab was applied between 3 and $5 \mathrm{~h}$ ). EPSPs that are unchanged (100\%) sensorin expression was independent of transcription, whereas the second was preceded by an increase in sensorin intensity, and red is high intensity) in sensory neuron cell bodies in control and at 0,2 , and $12 \mathrm{~h}$ after 5 -HT. ANOVA indicated a significant effect of treatment ( $\mathrm{df}=3,16 ; F=21.2 ; p<0.001$ ). After being normalized to staining intensity in control, staining at $0 \mathrm{~h}$ did not change but was significantly greater at 2 and $12 \mathrm{~h}(F=3.434$ and $p<0.05 ; F=16.228$ and $p<0.01$, respectively).

that PI3K activity is required for LTF, and rapamycin, a potent inhibitor of specific translation, blocks LTF produced by 5 -HT or sensorin (Hu et al., 2004a; Udo et al., 2005). Because PI3K and rapamycin can regulate protein synthesis at distal sites in neurons (Beaumont et al., 2001; Tang et al., 2002; Cammalleri et al., 2003; Schratt et al., 2004; Takei et al., 2004; Lee et al., 2005), we examined whether PI3K- and rapamycin-sensitive pathways participated in the rapid changes in sensorin expression immediately after 5-HT applications.

The PI3K inhibitor LY294002 (10 $\mu \mathrm{M})$ (Fig. 2) or rapamycin (50 nM) (Fig. 3 ) blocked the rapid increase in sensorin immedi- 
A
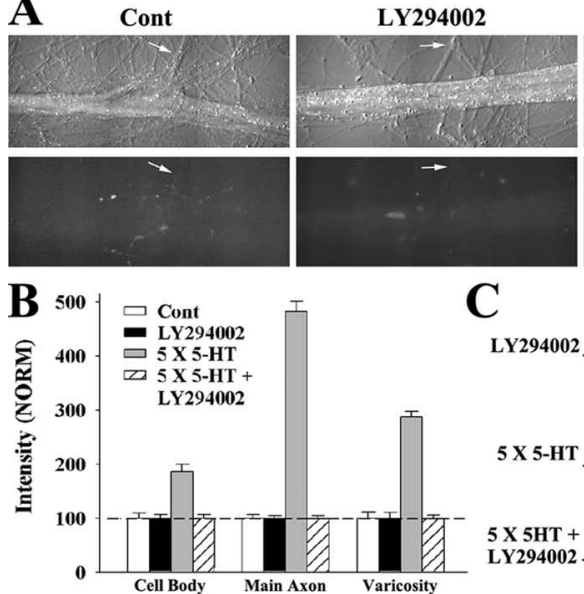

C

5X5-HT

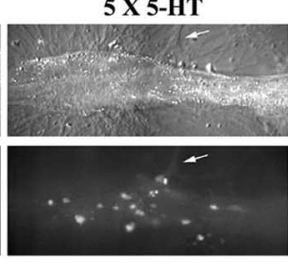

5 X 5-HT + LY294002
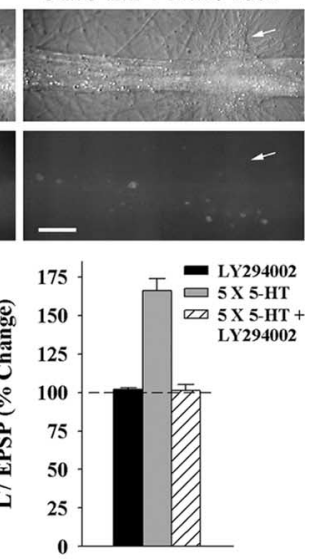

Figure 2. PI3K activity is required for the rapid increase in sensorin. $\boldsymbol{A}$, Nomarski contrast (top) and sensorin immunofluorescent (bottom) images of cocultures immediately after ( $0 \mathrm{~h}$ ) 5-HT in the presence or absence of $\mathrm{LY} 294002$ mock applications in the presence or absence of $L$ Y294002. Staining in the axons (arrows) and varicosities was reduced significantly when 5-HT was applied in the presence of the drug. Scale bar, $50 \mu \mathrm{m}$. B, Summary of sensorin immunostaining immediately after $(0 \mathrm{~h})$ the respective treatments. Staining for each compartment after drug or $5-\mathrm{HT}$ treatments was normalized to the average staining for that compartment in control (Cont; dashed line at 100\%). ANOVA indicated a significant effect of treatment ( $\mathrm{df}=6,50 ; F=85.383$; $p<0.001)$. Staining in cell body, axon, and varicosities increased significantly with 5 -HT alone $(F=11.598$ and $p<0.01 ; F=$ 191.68 and $p<0.01 ; F=51.743$ and $p<0.01$, respectively). In the presence of $\mathrm{LY} 294002,5-\mathrm{HT}$ failed to increase staining in all compartments. Treatment with LY294002 alone had little effect on sensorin staining. C, LY294002 blocked LTF produced by 5-HT. EPSPs were recorded before and $24 \mathrm{~h}$ after the respective treatments. ANOVA indicated a significant effect of treatment $(\mathrm{df}=2$, $23 ; F=59.819 ; p<0.001)$. LY294002 blocked the increase in EPSP produced by 5 -HT $(F=46.836 ; p<0.01)$. LY294002 did not affect baseline synaptic transmission. Calibration: vertical, $20 \mathrm{mV}$; horizontal, $25 \mathrm{~ms}$.
A
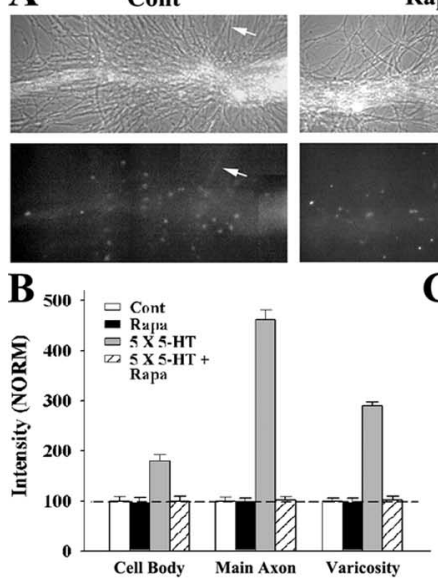

Rapa

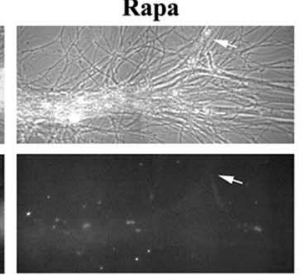

C

\begin{abstract}
C
\end{abstract}

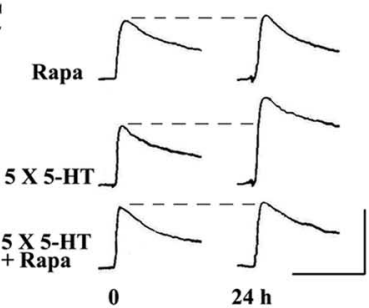

5 X 5-HT + Rapa

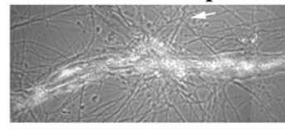

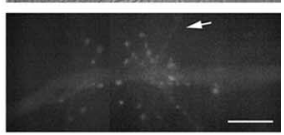

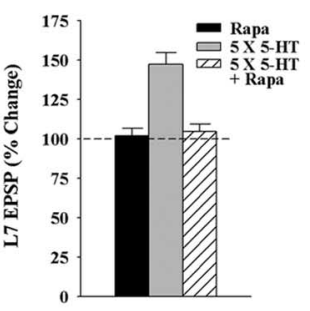

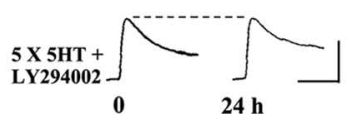

Figure 3. Rapamycin blocks the rapid increase in sensorin produced by 5-HT. $\boldsymbol{A}$, Nomarski contrast (top) and sensorin immunofluorescent (bottom) images of cocultures immediately after $(0 \mathrm{~h})$ mock applications in the presence or absence of rapamycin (Rapa) or $5 \times 5-\mathrm{HT}$ in the presence or absence of Rapa. Staining in the axons (arrows) and varicosities was reduced significantly when 5 -HT was applied in the presence of the drug. Scale bar, $50 \mu \mathrm{m}$. B, Summary of sensorin immunostaining immediately after $(0 \mathrm{~h})$ the respective treatments. Staining for each compartment after drug or 5 -HT treatments was normalized to the average staining for that compartment in control (Cont; dashed line at 100\%). ANOVA indicated a significant effect of treatment $(\mathrm{df}=6$, $48 ; F=55.004 ; p<0.001)$. Staining in cell body, axon, and varicosities increased significantly with $5-\mathrm{HT}(F=11.037$ and $p<$ $0.01 ; F=161.508$ and $p<0.01 ; F=102.023$ and $p<0.01$, respectively). In the presence of Rapa, 5 -HT failed to increase staining in all compartments. Treatment with rapamycin alone had little effect on sensorin staining. C, Rapamycin blocked LTF produced by 5 -HT. EPSPs were recorded before and $24 \mathrm{~h}$ after the respective treatments. ANOVA indicated a significant effect of treatment (df $=2,21 ; F=13.694 ; p<0.001)$. Rapamycin blocked the increase in EPSP produced by 5 -HT $(F=18.419 ; p<0.01)$. Rapamycin alone did not affect baseline synaptic transmission. Calibration: vertical, $20 \mathrm{mV}$; horizontal, $25 \mathrm{~ms}$.

with only 5 -HT ( $n=7$ cultures) resulted in a significant increase in sensorin staining in the cell body (186 $\pm 14 \%)$, in the axon $(482 \pm 20 \%)$, and in the varicosities $(287 \pm 11 \%)$. Treatment with the PI3K inhibitor alone failed to alter sensorin staining in all compartments (Fig. $2 A, B$ ). In contrast, blocking PKA activity during 5-HT with the PKA inhibitor KT5720 had only a modest effect on the rapid increase in sensorin protein (images not shown). Compared with controls (normalized to $100 \%$ for each compartment; $n=6$ cultures), applications of 5-HT in the presence of KT5720 ( $n=8$ cultures) increased staining for sensorin in the cell body (144 $\pm 6 \%$ ), axon (343 $\pm 13 \%)$, and varicosities $(240 \pm 9.0 \%)$. These changes in sensorin produced by 5 -HT in the presence of KT5720 were comparable with the increases produced by 5 -HT alone $(n=7$ cultures) in the cell body (163 $\pm 9 \%)$, axon $(492 \pm 28 \%)$, and varicosities (269 \pm $10 \%)$. Although interfering with PKA during this period affects other processes necessary for LTF, it appears that PI3K activity selectively mediates the rapid increases in sensorin with 5-HT.

Incubation with LY294002 also blocked LTF produced by 5-HT (Fig. $2 C)$. The change in EPSP amplitude $24 \mathrm{~h}$ after 5-HT was blocked by the PI3K inhibitor $(n=12 ; 101.4 \pm 3.7 \%)$ when compared with treatment with 5-HT only $(n=7 ; 166.0 \pm 8.1 \%)$. Treatment with LY294002 alone did not alter baseline EPSP amplitude $(n=7 ; 102.1 \pm 1.0 \%)$. Thus, PI3K activity during this early phase is required for both the increase in sensorin synthesis and LTF.

Rapamycin applied during 5-HT applications, which blocked LTF, also blocked the rapid increase in sensorin synthesis in all parts of the sensory neuron (Fig. 3). Compared with controls ( $n=7$ cultures; normalized to $100 \%$ ), rapamycin ( $n=7$ cultures) blocked the 5-HT-induced increase in sensorin staining in the cell body ( $99 \pm 10 \%)$, in the axon $(102 \pm 7 \%)$, and in the varicosities $(101 \pm 8 \%)$. Treatment with 5 -HT produced the expected increases in staining in each compartment, and rapamycin produced no significant reduction in staining when compared with controls (Fig. 3A,B). Rapamycin also blocked LTF produced by 5-HT (Fig. ately after treatment with 5-HT $(0 \mathrm{~h})$. When compared with controls $(n=6$ cultures; staining in each compartment normalized to $100 \%$ ), the PI3K inhibitor ( $n=9$ cultures) blocked the increase in sensorin staining in the cell body ( $99 \pm 7 \%)$, in the axon $(99 \pm 6 \%)$, and in varicosities $(98 \pm 7 \%)$. Treatment
3C). Rapamycin blocked the change in EPSP amplitude $24 \mathrm{~h}$ after 5 -HT ( $n=10$ cultures; $104.9 \pm 4.5 \%$ ) when compared with an increase in EPSP amplitude of $147.4 \pm 7.4 \%$ after treatment with 5 -HT alone ( $n=7$ cultures). Rapamycin alone ( $n=7$ cultures) did not alter baseline EPSP amplitude 
$(101.2 \pm 1.8 \%)$. The rapid changes in sensorin produced by 5 -HT also was regulated by rapamycin-sensitive protein synthesis.

\section{$\mathrm{PI} 3 \mathrm{~K}$ and rapamycin regulate sensorin levels at isolated sensory neuron processes}

After the cell body is removed, 5-HT produces a translation-dependent form of LTF at isolated sensory neuron synapses (Liu et al., 2003; Grabham et al., 2005). We examined whether 5 -HT also produces a rapid increase in sensorin in isolated axons and varicosities and whether the PI3K activity and rapamycin regulate that increase in expression. At $3 \mathrm{~h}$ after removal of the sensory neuron cell bodies the cultures were treated with 5-HT or control applications in the presence or absence of either LY294002 or rapamycin. Cultures were fixed immediately after washout of the last 5-HT application $(0 \mathrm{~h})$ or $2 \mathrm{~h}$ later $(2 \mathrm{~h})$. Then, the cultures were processed for sensorin immunostaining.

In the absence of the sensory neuron cell body, 5-HT produced a significant increase in sensorin staining in the axon and varicosities of sensory neuron at $0 \mathrm{~h}$, which returned to or below baseline at $2 \mathrm{~h}$ after the treatment with 5-HT (Fig. 4A, $B$ ). Compared with controls $(n=7$ cultures; staining in each compartment normalized to $100 \%)$, 5 -HT produced increases in staining at $0 \mathrm{~h}$ ( $n=8$ cultures) in the axon $(380 \pm 17 \%)$ and in the varicosities $(254 \pm 18 \%)$. Staining in the axon was reduced to control levels $(99 \pm 6 \%)$ and in the varicosities to below control levels $(58 \pm 3 \%)$ at $2 \mathrm{~h}$ after 5 -HT $(n=8 \mathrm{cul}$ tures). The increases in sensorin staining at $0 \mathrm{~h}$ in the axon and varicosities in the absence of the sensory neuron cell body were blocked by the PI3K inhibitor LY294002 and rapamycin (Fig. 4C,D). Compared with controls $(n=6$ cultures; staining in each compartment normalized to $100 \%)$, the PI3K inhibitor ( $n=7$ cultures) and rapamycin ( $n=7$ cultures) blocked the increase in sensorin staining produced by 5 -HT at $0 \mathrm{~h}$ in the axon $(102 \pm 7$ and $100 \pm 6 \%$, respectively) and in the varicosities (99 \pm 13 and $101 \pm 12 \%$, respectively). Sensorin staining was increased by 5 -HT $(n=6$ cultures) both in the axon $(359 \pm 23 \%)$ and in the varicosities $(271 \pm 13 \%)$. The rapid local translation of sensorin and its release from distal processes are regulated by $5-\mathrm{HT}$ and are likely to contribute to LTF. Both PI3K activity and rapamycin regulate translation of sensorin in all parts of the sensory neuron.

\section{Type II PKA regulates secretion of sensorin and the} autocrine response of sensorin

The activation of PKA by 5-HT appears to affect sensory neurons upstream of the release of sensorin and activation of its autocrine responses (Hu et al., 2004a). In Aplysia neurons, type I and type II
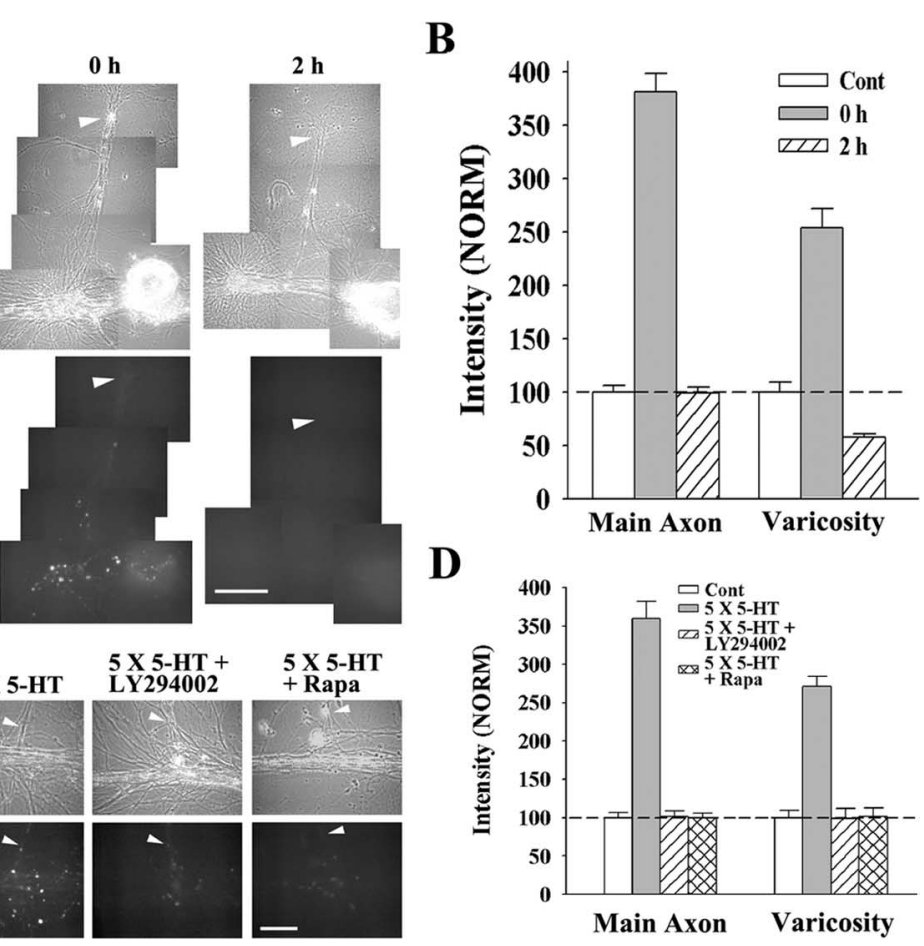

Figure 4. Inhibitor of PI3K or rapamycin blocks the 5-HT-induced increase in sensorin at distal sites in the absence of sensory neuron cell body. $A, B$, In the absence of the cell body (at each arrow), 5 -HT produced a rapid increase in sensorin immediately after 5 -HT $(0 \mathrm{~h})$ that was reversed by $2 \mathrm{~h}$. Shown are Nomarski contrast (top) and sensorin immunofluorescent (bottom) images of not at $2 \mathrm{~h}$ after 5 -HT. Scale bar, $50 \mu \mathrm{m}$. Summary of sensorin immunostaining in axon and varicosities after contro ked the rapid increases in sensorin produced by 5-HT. Shown are Nomarski contrast (top) and sensorin immunofluorescent ) images of cocultures ( $C$ at $0 \mathrm{~h}$ after mock applications (Cont) or 5-HT applications in the presence or absence of the drug. rapamycin. Scale bar, $50 \mu \mathrm{m}$. Summary of sensorin immunostaining in axon and varicosities immediately after control or 5-HT 100\%) A (17). ANOVA indicates a significant effect of treatment $(\mathrm{df}=3,22 ; F=17.536 ; p<0.001$. At $0 \mathrm{~h}$, there is a significant increase Y294002 and rapamycin blocked the increases produced by $5-\mathrm{HT}$ in both axon and varicosities so that the staining in each was not different from control and significantly lower than that produced by 5 -HT alone ( $F=79.17$ and 30.715 and $p<0.01$, respectively, comparing 5-HT with 5-HT plus LY294002; $F=80.138$ and 28.561 and $p<0.01$, respectively, comparing 5-HT with 5-HT plus rapamycin).

PKA are concentrated in different cellular compartments. Type I PKA is concentrated in the sensory neuron cell body, and type II PKA is concentrated at synaptic sites at which its interactions with anchoring proteins (AKAPs) are required for producing LTF. Incubation with a permeable form of a peptide (S-Ht31) that interferes with type II PKA-AKAP interaction blocked LTF (Liu et al., 2004). We therefore examined whether this interaction is required for sensorin secretion.

Blocking PKA-AKAP interaction during the first $2 \mathrm{~h}$ after the treatment with 5-HT blocked sensorin secretion and LTF (Fig. 5). Incubation with the permeable peptide inhibitor of PKA-AKAP interactions ( $\mathrm{S}-\mathrm{Ht} 31 ; 10 \mu \mathrm{M}$ ) for $2 \mathrm{~h}$ beginning immediately after the last 5-HT application blocked the reduction in sensorin staining detected $2 \mathrm{~h}$ after 5-HT (Fig. 5A, B). Incubation with the permeable form of the control peptide ( 10 $\mu \mathrm{M}$; S-Ht31P, which has a single amino acid substitution, 
A
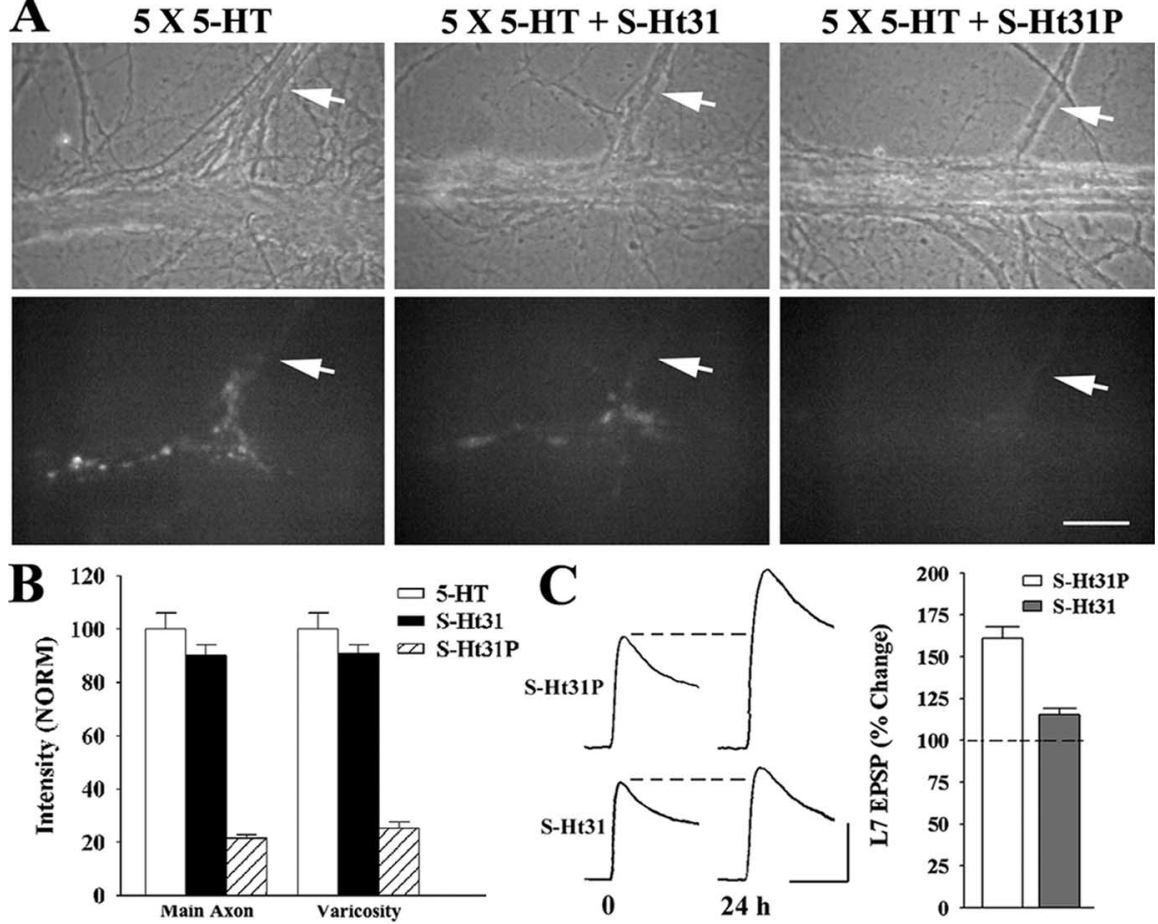

Figure 5. Type II PKA activity is required for the release of sensorin after 5-HT. $\boldsymbol{A}$, Nomarski contrast (top) and sensorin immunofluorescent (bottom) images of cocultures immediately after $5 \times 5$-HT and $2 \mathrm{~h}$ after $5 \times 5-\mathrm{HT}$ and incubated for those $2 \mathrm{~h}$ with the active peptide inhibitor of type II PKA interaction with AKAPs (S-Ht31) or with the inactive peptide (S-Ht31P). Staining in the axons (arrows) and varicosities was reduced significantly only when cultures were incubated with the inactive peptide. The active peptide inhibitor blocked the decline in sensorin immunostaining. Scale bar, $50 \mu \mathrm{m}$. B. Summary of sensorin immunostaining in the sensory neuron axon and varicosities after the respective treatments. The active peptide inhibitor $\mathrm{S}-\mathrm{Ht} 31$ blocked the decline in sensorin staining $2 \mathrm{~h}$ after 5 -HT. ANOVA indicated a significant effect of treatment ( $\mathrm{df}=2,19 ; F=16.43 ; p<0.001$ ). Compared with the high staining produced at $0 \mathrm{~h}$ after $5-\mathrm{HT}$ alone (normalized to $100 \%$ ), staining declined significantly in axons and varicosities $(F=94.766$ and $F=65.153$, respectively; $p<0.01)$ when the cultures were incubated with the control peptide (S-Ht31P). Incubation with the active peptide (S-Ht31) blocked the decline, and staining was not significantly different from the high level of staining produced immediately after 5-HT. C, Incubation with the active inhibitor between 0 and $2 \mathrm{~h}$ after 5 -HT blocked LTF. EPSPs were recorded before (0) and $24 \mathrm{~h}$ after $5 \times 5-\mathrm{HT}$. Immediately after $5-\mathrm{HT}$, the cultures were incubated for $2 \mathrm{~h}$ with the control peptide (S-Ht31P) or the active inhibitor peptide (S-Ht31). The active peptide attenuated the increase in EPSP at 24 h. Calibration: vertical, $20 \mathrm{mV}$; horizontal, $25 \mathrm{~ms}$. ANOVA indicated a significant effect of treatment ( $\mathrm{df}=1,23 ; F=21.907$; $p<0.001$ ). The increase in EPSP amplitude with 5 -HT and incubation with the inactive peptide were significantly greater than the change produced by 5 -HT and incubation with the active inhibitor $(F=39.423 ; p<0.01)$.
A

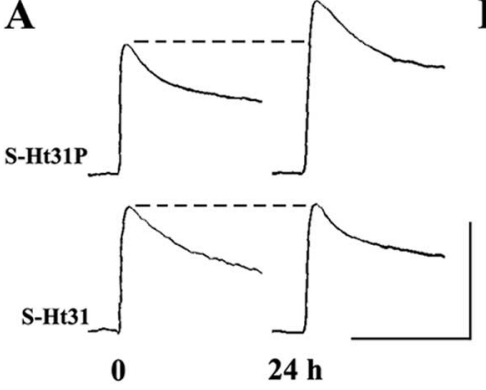

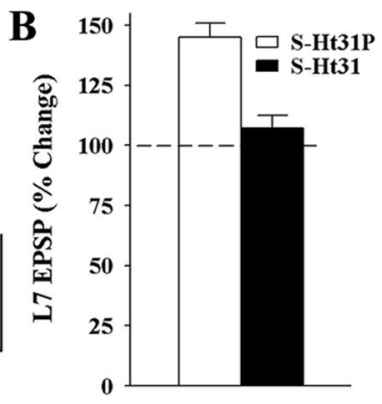

Figure 6. Type II PKA activity is required for sensorin-induced LTF. $A$, EPSPs were recorded in $\mathrm{L} 7 \mathrm{before}(0)$ and $24 \mathrm{~h}$ after $(24)$ the indicated treatments. Cultures were exposed to $1 \times 5-\mathrm{HT}(5$ $\mathrm{min})$, followed immediately after rinsing with a $2 \mathrm{~h}$ incubation with sensorin. Beginning $60 \mathrm{~min}$ before sensorin application the cultures were incubated with either the control peptide (S$\mathrm{Ht} 31 \mathrm{P}$ ) or the active peptide (S-Ht31). 5-HT was added during the last $5 \mathrm{~min}$ and then rinsed out before sensorin was added. The active peptide blocked LTF, whereas the control peptide did not. Calibration: vertical, $20 \mathrm{mV}$; horizontal, $25 \mathrm{~ms}$. $\boldsymbol{B}$, Summary of changes in EPSP amplitudes produced by $1 \times 5$-HT plus sensorin in the presence of control or active peptide. ANOVA indicated a significant effect of treatment ( $\mathrm{df}=1,17 ; F=29.507 ; p<0.001)$. LTF was blocked $(F=22.312 ; p<0.01)$ when the active peptide $(\mathrm{S}-\mathrm{Ht} 31)$ was present during the $5 \mathrm{~min}$ application of $5-\mathrm{HT}$. thereby preventing its inhibition of PKA-AKAP interaction) failed to block the decline in sensorin staining at $2 \mathrm{~h}$ after 5-HT. Compared with the high level of staining at $0 \mathrm{~h}$ after 5 - $\mathrm{HT}(n=6$; staining in each compartment normalized to $100 \%)$, incubation with active peptide ( $n=8$ cultures) blocked the expected decline in sensorin staining in the axon $(90 \pm 5 \%)$ and in the varicosities $(87 \pm 5 \%)$. In contrast, treatment with the control peptide for $2 \mathrm{~h}$ after 5-HT did not affect the expected decline in staining in each compartment; staining intensity declined to $21 \pm 2 \%$ in the axon and to $25 \pm 2 \%$ in the varicosities. Incubation with the active peptide during the same time period $(0-2 \mathrm{~h}$ after 5-HT) also attenuated LTF (Fig. 5C). Incubation with S-Ht31 peptide significantly reduced the change in EPSP amplitude $24 \mathrm{~h}$ after 5 -HT $(115.3 \pm 3.8 \%$; $n=15$ cultures), whereas incubation with the inactive peptide S-Ht31P produced an increase in EPSP amplitude of $160.9 \pm 6.9 \%(n=10$ cultures $)$. Both the decline in sensorin staining, an indicator of sensorin secretion, and LTF required the proper functioning of type II PKA. In contrast, blocking PI3K activity during the $2 \mathrm{~h}$ period after 5 -HT did not interfere with the decline in sensorin by $2 \mathrm{~h}$. Compared with the high level of sensorin staining at $0 \mathrm{~h}$ after 5 -HT (normalized to $100 \%$ in each compartment; $n=$ 8 cultures), the reduction in sensorin staining was not blocked in the axon $(23 \pm 2 \%)$ or in the varicosities $(28 \pm$ $3 \%)$ when the PI3K inhibitor LY294002 was present for $2 \mathrm{~h}$ after the treatment with 5-HT ( $n=9$ cultures). These reductions were comparable with those seen in the axons $(22 \pm 2 \%)$ and varicosities $(25 \pm 2 \%) 2 \mathrm{~h}$ after 5 -HT alone ( $n=7$ cultures). Thus, the activity of type II PKA was critical for the decline in sensorin (secretion) $2 \mathrm{~h}$ after PI3K- and rapamycin-sensitive activities produced an increase in sensorin synthesis.

In addition to its role in sensorin secretion, PKA activity also was required for sensorin to produce LTF. Sensorin itself ( $2 \mathrm{~h}$ incubation) produced LTF only when preceded by a single 5 min application of 5-HT. Blocking PKA activity with KT5720 during the 5-HT application blocked sensorininduced LTF (Hu et al., 2004a). We examined whether interfering with type II PKA interaction with AKAPs during the 5-HT application also attenuates sensorin-induced LTF.

Incubation with the active peptide (S-Ht31) before the 5 min application of 5-HT blocked sensorin-induced LTF (Fig. 6). The change in EPSP amplitude $24 \mathrm{~h}$ later was only $107.2 \pm$ $5.4 \%(n=10)$. In contrast, when incubated with the inactive peptide (S-Ht31P), sensorin induced a change in EPSP amplitude $24 \mathrm{~h}$ later of $145.1 \pm 5.8 \%$ ( $n=9$ cultures). Incubation with LY294002 during the single application of 5-HT failed to block sensorin-induced LTF (data not shown). Thus, proper 
functioning of type II PKA is critical for sensorin to produce LTF.

\section{Activation of PI3K and type II PKA is required for MAPK activation and translocation}

5-HT activates and translocates p42/44 MAPK (Martin et al., 1997; Purcell et al., 2003) that is mediated by secreted sensorin (Hu et al., 2004a). Our data indicate that the sensorin secretion that produces LTF requires first a PI3Kdependent increase in sensorin synthesis, followed by a PKA-dependent regulation of secretion and of the ability of sensorin to produce LTF (Figs. 2-6). Because sensorin mediates MAPK activation and translocation, we predict that MAPK activation by 5 -HT would be blocked when LY294002 is applied during 5-HT applications or when the peptide inhibitor of type II PKA-AKAP interactions ( $\mathrm{S}-\mathrm{Ht} 31$ ) is applied immediately after the last application of 5-HT. We used immunocytochemistry for detecting the phosphorylated forms of p42/44 MAPK (Murray et al., 1998) $1 \mathrm{~h}$ after the last application of 5-HT (Martin et al., 1997; Hu et al., 2004a).

Incubation with LY294002 during the applications of 5-HT or S-Ht31 immediately after the last application of 5-HT blocked MAPK phosphorylation and translocation into sensory neuron nuclei that are produced by 5-HT (Fig. 7). Incubation with the inactive peptide S-Ht31P failed to block MAPK phosphorylation and translocation. After 5-HT, the staining intensity over the entire cell body and in the nucleus was significantly higher (nearly twofold and more than threefold, respectively) when compared with staining in cultures treated with 5-HT in the presence of LY294002 (Fig. 7 A, B, top portions). Incubation with the active peptide after $5-\mathrm{HT}$ also reduced MAPK phosphorylation compared with that observed when incubated with the inactive peptide after 5-HT. Staining in the cell body and the nucleus was twofold and nearly fourfold greater when cultures were incubated with inactive peptide S-Ht31P after 5-HT. Thus, the activation and translocation of p42/44 MAPK by 5 -HT require the sequential activities of PI3K and type II PKA.

\section{Discussion}

Our findings indicate that the secretion of a neuropeptide that is critical for LTF at Aplysia sensory neuron synapses requires the previous actions of two signaling pathways: the PI3K pathway and type II PKA. The rapid increase of sensorin protein synthesis, including local translation at distal sensory neuron varicosities, is regulated by PI3K activity and is blocked by rapamycin. The newly synthesized sensorin that is secreted from distal processes is mediated by activation of type II PKA during the period immediately after the treatment with 5-HT. The secretion of sensorin and type II PKA activates MAPK and produces LTF. Thus, the sequential and interconnected activities of PI3K, PKA, and MAPK are regulated by 5-HT and sensorin to produce LTF.

\section{PI3K and rapamycin regulate the synthesis of sensorin}

Sensorin protein synthesis in the sensory neuron is enhanced significantly and rapidly by 5 -HT. The rapid increase in sensorin protein is not correlated with an increase in sensorin mRNA. Moreover, a significant increase in protein expression is detected even when 5-HT is applied after the cell bodies of sensory neurons are removed. Thus, 5-HT induces an increase in sensorin protein synthesis throughout the sensory neuron, including the distal varicosities.

In Aplysia sensory neurons, 5-HT leads to the activation of several kinases. Activation of PKA (Kandel and Schwartz, 1982; Greenberg et al., 1987; Schacher et al., 1988, 1993; Wu et al., 1995; Chang et al., 2000; Liu et al., 2004) and PKC (Sacktor and Schwartz, 1990; Sossin and Schwartz, 1992; Sutton and Carew, 2000; Manseau et al., 2001; Sutton et al., 2004) contribute to short-, intermediate-, or long-term facilitation at sensory neuron synapses. However, PKC activity, required for short- and intermediate-term facilitation, does not appear to be involved with sensorin expression or secretion. Blocking PKC activity during this period is not required for LTF produced by 5 -HT or sensorin (Wu et al., 1995; Hu et al., 2003, 2004a). PKA activation during this period is required for long-term forms of facilitation (Greenberg et al., 1987; Schacher et al., 1988, 1993; Liu et al., 2004). However, blocking PKA activity during the 5-HT applications has only a modest effect on the increase in sensorin expres- 
sion. MAPK activation, which is critical for LTF (Martin et al., 1997; Purcell et al., 2003; Hu et al., 2004a), is not likely to be involved with the early rapid increase in sensorin. MAPK activation occurs later and only after significant secretion of sensorin (Martin et al., 1997; Purcell et al., 2003; Hu et al., 2004a) (see below).

Another candidate pathway that might regulate sensorin synthesis is PI3K, recently implicated in LTF (Udo et al., 2005). PI3K activation can be initiated via the same G-protein-coupled receptors that activate PKA or PKC (Khan et al., 2001; Pepio et al., 2002; Brock et al., 2003). Repeated applications of 5-HT would then lead to phosphorylation of a PI3K substrate Akt/protein kinase B (J. Liu, J.-Y. Hu, J. Schwartz, and S. Schacher, unpublished observations). One of the downstream consequences of PI3K activity is the activation of rapamycin-sensitive protein synthesis (Yanow et al., 1998; Dufner and Thomas, 1999), which also is required for LTF (Casadio et al., 1999; Hu et al., 2004a). The rapamycin-sensitive synthesis of sensorin also could be affected by 5 -HT by a pathway that is independent of PI3K (Khan et al., 2001). PI3K activity and rapamycin-sensitive synthesis are important at distal sites, because both LY294002 and rapamycin block the increase in sensorin at varicosities even in the absence of sensory neuron cell bodies. The local accumulation of sensorin mRNA at varicosities (Schacher et al., 1999; Hu et al., 2002) can serve as the template for the local translation of sensorin. In the absence of the sensory neuron cell body, protein synthesisdependent LTF and the initial formation of new presynaptic varicosities (Liu et al., 2003; Grabham et al., 2005) are likely to be mediated by the increase in the local synthesis and secretion of sensorin (Hu et al., 2004a,b). Thus, both the machinery for protein synthesis and its regulation are distributed at various locations in the sensory neuron. Sensorin joins the list of proteins for which the local synthesis contributes to long-term synaptic plasticity (Miller et al., 2002; Steward and Worley, 2002; Huang et al., 2005; Smith et al., 2005). The stimulus-induced regulation of neuropeptide synthesis is also observed for BDNF after stimuli that produce long-lasting forms of LTP in the hippocampus (Hall et al., 2000; Pang et al., 2004).

\section{Type II PKA regulates sensorin secretion and responses that are critical for LTF}

Sensorin secretion is enhanced significantly by repeated applications of 5-HT (Hu et al., 2004a). Medium collected from cocultures $2 \mathrm{~h}$ after the treatment with 5-HT has significant levels of sensorin. This "conditioned medium" containing secreted sensorin will evoke LTF when it is applied to naive cocultures after a single application of 5-HT (sensorin-induced LTF) [Hu et al. (2004a), their Fig. 3]. The significant decline in the newly synthesized sensorin in the axons and varicosities of the sensory neuron during the $2 \mathrm{~h}$ period after the treatment with 5-HT corresponds with the period when sensorin is secreted. The secretion during this period is critical for LTF because anti-sensorin Ab applied during this $2 \mathrm{~h}$ period blocked LTF, whereas incubation for a $2 \mathrm{~h}$ period with anti-sensorin $\mathrm{Ab}$ beginning at $3 \mathrm{~h}$ after the treatment with 5-HT failed to interfere with LTF. Which signaling pathway regulates sensorin secretion immediately after the treatment with 5-HT?

Type II PKA activity, specifically the phosphorylation of substrates near the membrane mediated via interactions between the regulatory subunit of type II PKA (RII) with anchoring proteins (AKAPs) (Moita et al., 2002; Liu et al., 2004), is required for the enhanced secretion of sensorin. This activity might include phosphorylation of vesicle proteins that would facilitate the enhanced secretion of the neuropeptide (Goodman et al., 1996; Han et al., 1999; Jovanovic et al., 2000; Angers et al., 2002). Because cAMP is enhanced in a persistent manner by the repeated applications of 5-HT (Bernier et al., 1982; Greenberg et al., 1987; Muller and Carew, 1998; Liu et al., 2004), the increased PKA activity at varicosities could regulate the large release of sensorin needed to produce LTF. Type II PKA activity at or near the membrane also regulates the ability of sensorin to activate autocrine responses in the sensory neurons (Hu et al., 2004a) and to produce LTF. PKA activity near the membrane may lead to the phosphorylation of sensorin receptors, molecules involved with receptor trafficking, or the associated molecules for activating downstream signaling pathways (Meyer-Franke et al., 1998; Du et al., 2000; Patterson et al., 2001).

Our results suggest that the sequential activation by $5-\mathrm{HT}$ of specific signaling pathways is critical for the development of LTF. The type II PKA-dependent secretion of the newly synthesized sensorin follows the rapid PI3K- and rapamycin-dependent increase in sensorin synthesis at distal sites. Sensorin secretion and the type II PKA-dependent regulation of the autocrine responses of sensorin subsequently lead to the activation of MAPK ( $\mathrm{Hu}$ et al., 2004a; Ormond et al., 2004). Because all of these signaling pathways are present in the distal processes of the sensory neurons, local synapse-specific changes in the synthesis and secretion of sensorin and activation of downstream signaling pathways can participate in the "tagging" of activated synapses for expressing long-term synapse-specific plasticity (Frey and Morris, 1997; Casadio et al., 1999). Later changes in sensorin mRNA expression, perhaps produced by MAPK translocation and persistent PKA activity in the sensory neuron nuclei that regulate the activity of transcription factors (Dash et al., 1990; Bacskai et al., 1993; Martin et al., 1997; Casadio et al., 1999; Chain et al., 1999; Roberson et al., 1999; Davis et al., 2000; Scott et al., 2002), might contribute to the second wave of increased sensorin synthesis detected by $12 \mathrm{~h}$ after 5-HT. A second wave of protein synthesis $6-12 \mathrm{~h}$ after 5-HT is critical for the long-lasting form of LTF detected at $72 \mathrm{~h}$ (Casadio et al., 1999; Chain et al., 1999; Sherff and Carew, 1999). This second increase in sensorin protein may produce a proportional increase in the constitutive secretion of sensorin needed to maintain the synaptic changes. Long-term maintenance of synaptic contacts requires the constitutive secretion of sensorin ( $\mathrm{Hu}$ et al., 2004 b). Thus, combined with the earlier changes produced by the activation of the various signaling pathways by 5 -HT and sensorin, long-term changes in synapse function and structure are initiated and maintained.

\section{References}

Angers A, Fioravante D, Chin J, Cleary LJ, Bean AJ, Byrne JH (2002) Serotonin stimulates phosphorylation of Aplysia synapsin and alters its subcellular distribution. J Neurosci 22:5412-5422.

Bacskai BJ, Hochner B, Mahaut-Smith M, Adams SR, Kaang BK, Kandel ER, Tsien RY (1993) Spatially resolved dynamics of cAMP and protein kinase A subunits in Aplysia sensory neurons. Science 260:222-226.

Bailey CH, Montarolo P, Chen M, Kandel ER, Schacher S (1992) Inhibitors of protein and RNA synthesis block structural changes that accompany long-term heterosynaptic plasticity in Aplysia. Neuron 9:749-758.

Bailey CH, Kaang BK, Chen M, Martin KC, Lim CS, Casadio A, Kandel ER (1997) Mutation in the phosphorylation sites of MAP kinase blocks learning-related internalization of apCAM in Aplysia sensory neurons. Neuron 18:913-924.

Balkowiec A, Katz DM (2002) Cellular mechanisms regulating activitydependent release of native brain-derived neurotrophic factor from hippocampal neurons. J Neurosci 22:10399-10407.

Bartsch D, Ghirardi M, Skehel PA, Karl KA, Herder SP Chen M, Bailey CH, Kandel ER (1995) Aplysia CREB2 represses long-term facilitation: relief 
of repression converts transient facilitation into long-term functional and structural change. Cell 83:979-992.

Bartsch D, Casadio A, Karl KA, Serodio P, Kandel ER (1998) CREB1 encodes a nuclear activator, a repressor, and a cytoplasmic modulator that form a regulatory unit critical for long-term facilitation. Cell 95:211-223.

Beaumont V, Zhong N, Fletcher R, Froemke RC, Zucker RS (2001) Phosphorylation and local presynaptic protein synthesis in calcium- and calcineurin-dependent induction of crayfish long-term facilitation. Neuron 32:489-501.

Bernier L, Castellucci VF, Kandel ER, Schwartz JH (1982) Facilitatory transmitter causes a selective and prolonged increase in adenosine $3^{\prime}: 5^{\prime}$ monophosphate in sensory neurons mediating the gill and siphon withdrawal reflex in Aplysia. J Neurosci 2:1682-1691.

Bliss TV, Collingridge GL (1993) A synaptic model of memory: long-term potentiation in the hippocampus. Nature 361:31-39.

Brock C, Schaefer M, Reusch HP, Czupalla C, Michalke M, Spicher K, Schultz G, Nurnberg B (2003) Roles of G $\beta \gamma$ in membrane recruitment and activation of p110 $\gamma / \mathrm{p} 101$ phosphoinositide 3-kinase $\gamma$. J Cell Biol 160:89-99.

Cammalleri M, Lutjens R, Berton F, King AR, Simpson C, Francesconi W, Sanna PP (2003) Time-restricted role for dendritic activation of the mTOR-p70S6K pathway in the induction of late-phase long-term potentiation in the CA1. Proc Natl Acad Sci USA 100:14368-14373.

Casadio A, Martin KC, Giustetto M, Zhu H, Chen M, Bartsch D, Bailey CH, Kandel ER (1999) A transient, neuron-wide form of CREB-mediated long-term facilitation can be stabilized at specific synapses by local protein synthesis. Cell 99:221-237.

Chain DG, Schwartz JH, Hegde AN (1999) Ubiquitin-mediated proteolysis in learning and memory. Mol Neurobiol 20:125-142.

Chang DJ, Li XC, Lee YS, Kim HK, Kim US, Cho NJ, Lo X, Weiss KR, Kandel ER, Kaang BK (2000) Activation of a heterologously expressed octopamine receptor coupled only to adenylyl cyclase produces all of the features of presynaptic facilitation in Aplysia sensory neurons. Proc Natl Acad Sci USA 97:1829-1834.

Dash PK, Hochner B, Kandel ER (1990) Injection of the cAMP-responsive element into the nucleus of Aplysia sensory neurons blocks long-term facilitation. Nature 345:718-721.

Davis S, Vanhoutte P, Pages C, Caboche J, Laroche S (2000) The MAPK/ ERK cascade targets both Elk-1 and cAMP response element-binding protein to control long-term potentiation-dependent gene expression in the dentate gyrus in vivo. J Neurosci 20:4563-4572.

Du J, Feng L, Yang F, Lu B (2000) Activity- and calcium-dependent modulation of surface expression of brain-derived neurotrophic factor receptors in hippocampal neurons. J Cell Biol 150:1423-1434.

Dufner A, Thomas G (1999) Ribosomal S6 kinase signaling and the control of translation. Exp Cell Res 253:100-109.

Frey U, Morris RG (1997) Synaptic tagging and long-term potentiation. Nature 385:533-536.

Frey U, Huang YY, Kandel ER (1993) Effects of cAMP simulate a late stage of LTP in hippocampal CA1 neurons. Science 260:1661-1664.

Gartner A, Staiger V (2002) Neurotrophin secretion from hippocampal neurons evoked by long-term potentiation-inducing electrical stimulation patterns. Proc Natl Acad Sci USA 99:6386-6391.

Giustetto M, Hegde AN, Si K, Casadio A, Inokuchi K, Pei W, Kandel ER, Schwartz JH (2003) Axonal transport of eukaryotic translation elongation factor $1 \alpha$ mRNA couples transcription in the nucleus to long-term facilitation at the synapse. Proc Natl Acad Sci USA 100:13680-13685.

Goodman LJ, Valverde J, Lim F, Geschwind MD, Federoff HJ, Geller AI, Hefti F (1996) Regulated release and polarized localization of brain-derived neurotrophic factor in hippocampal neurons. Mol Cell Neurosci 7:222-238.

Grabham PW, Wu F, Schacher S, Goldberg DJ (2005) Initiating morphological changes associated with long-term facilitation in Aplysia is independent of transcription or translation in the cell body. J Neurobiol 64:202-212.

Greenberg SM, Castellucci VF, Bayley H, Schwartz JH (1987) A molecular mechanism for long-term sensitization in Aplysia. Nature 329:62-65.

Hall J, Thomas KL, Everitt BJ (2000) Rapid and selective induction of BDNF expression in the hippocampus during contextual learning. Nat Neurosci 3:533-535.

Han W, Ng YK, Axelrod D, Levitan ES (1999) Neuropeptide release by effi- cient recruitment of diffusing cytoplasmic secretory vesicles. Proc Natl Acad Sci USA 96:14577-14582.

Hu JY, Meng X, Schacher S (2002) Target interaction regulates distribution and stability of specific mRNAs. J Neurosci 22:2669-2678.

Hu JY, Meng X, Schacher S (2003) Redistribution of syntaxin mRNA in neuronal cell bodies regulates protein expression and transport during synapse formation and long-term synaptic plasticity. J Neurosci 23:1804-1815.

Hu JY, Glickman L, Wu F, Schacher S (2004a) Serotonin regulates the secretion and autocrine action of a neuropeptide to activate MAPK required for long-term facilitation in Aplysia. Neuron 43:373-385.

Hu JY, Goldman J, Wu F, Schacher S (2004b) Target-dependent release of a presynaptic neuropeptide regulates the formation and maturation of specific synapses in Aplysia. J Neurosci 24:9933-9943.

Huang F, Chotiner JK, Steward O (2005) The mRNA for elongation factor $1 \alpha$ is localized in dendrites and translated in response to treatments that induce long-term depression. J Neurosci 25:7199-7209.

Huang YY, Martin KC, Kandel ER (2000) Both protein kinase A and mitogen-activated protein kinase are required in the amygdala for the macromolecular synthesis-dependent late phase of long-term potentiation. J Neurosci 20:6317-6325.

Impey S, Obrietan K, Wong ST, Poser S, Yano S, Wayman G, Deloulme JC, Chan G, Storm DR (1998) Cross talk between ERK and PKA is required for $\mathrm{Ca}^{2+}$ stimulation of CREB-dependent transcription and ERK nuclear translocation. Neuron 21:869-983.

Jovanovic JN, Czernik AJ, Fienberg AA, Greengard P, Sihra TS (2000) Synapsins as mediators of BDNF-enhanced neurotransmitter release. Nat Neurosci 3:323-329.

Kandel ER, Schwartz JH (1982) Molecular biology of learning: modulation of transmitter release. Science 218:433-443.

Kang H, Welcher AA, Shelton D, Schuman EM (1997) Neurotrophins and time: different roles for TrkB signaling in hippocampal long-term potentiation. Neuron 19:653-664.

Khan A, Pepio AM, Sossin WS (2001) Serotonin activates S6 kinase in a rapamycin-sensitive manner in Aplysia synaptosomes. J Neurosci 21:382-391.

Lee CC, Huang CC, Wu MY, Hsu KS (2005) Insulin stimulates postsynaptic density-95 protein translation via the phosphoinositide 3-kinase-Aktmammalian target of rapamycin signaling pathway. J Biol Chem 280:18543-18550.

Lin CH, Yeh SH, Lu KT, Leu TH, Chang WC, Gean PW (2001) A role for the PI3K signaling pathway in fear conditioning and synaptic plasticity in the amygdala. Neuron 31:841-851.

Ling DS, Benardo LS, Serrano PA, Blace N, Kelly MT, Crary JF, Sacktor TC (2002) Protein kinase $M \zeta$ is necessary and sufficient for LTP maintenance. Nat Neurosci 5:295-296.

Lisman J, Schulman H, Cline H (2002) The molecular basis of CaMKII function in synaptic and behavioural memory. Nat Rev Neurosci 3:175-190.

Liu J, Schwartz JH (2003) The cytoplasmic polyadenylation element binding protein and polyadenylation of messenger RNA in Aplysia neurons. Brain Res 959:68-76.

Liu J, Hu JY, Schacher S, Schwartz JH (2004) The two regulatory subunits of Aplysia protein kinase A mediate distinct functions in producing synaptic plasticity. J Neurosci 24:2465-2474.

Liu K, Hu JY, Wang D, Schacher S (2003) Protein synthesis at synapse versus cell body: enhanced but transient expression of long-term facilitation at isolated synapses. J Neurobiol 56:275-286.

Lovinger DM, Routtenberg A (1988) Synapse-specific protein kinase C activation enhances maintenance of long-term potentiation in rat hippocampus. J Physiol (Lond) 400:321-333.

Lynch G, Larson J, Kelso S, Barrionuevo G, Schottler F (1983) Intracellular injections of EGTA block induction of hippocampal LTP. Nature 305:719-721.

Malenka RC, Bear MF (2004) LTP and LTD: an embarrassment of riches. Neuron 44:5-21.

Malinow R, Madison DV, Tsien RW (1988) Persistent protein kinase activity underlying long-term potentiation. Nature 335:820-824.

Man HY, Wang Q, Lu WY, Ju W, Ahmadian G, Liu L, D'Souza S, Wong TP, Taghibiglou C, Lu J, Becker LE, Pei L, Liu F, Wymann MP, MacDonald JF, Wang YT (2003) Activation of PI3K is required for AMPA receptor in- 
sertion during LTP of mEPSCs in cultured hippocampal neurons. Neuron 38:611-624.

Manseau F, Fan X, Hueftlein T, Sossin W, Castellucci VF (2001) $\mathrm{Ca}^{2+}$ independent protein kinase C Apl II mediates the serotonin-induced facilitation at depressed Aplysia sensorimotor synapses. J Neurosci 21:1247-1256.

Martin KC, Michael D, Rose JC, Barad M, Casadio A, Zhu H, Kandel ER (1997) MAP kinase translocates into the nucleus of the presynaptic cell and is required for long-term facilitation in Aplysia. Neuron 18:899-912.

Meyer-Franke A, Wilkinson GA, Kruttgen A, Hu M, Munro E, Hanson Jr MG, Reichardt LF, Barres BA (1998) Depolarization and cAMP elevation rapidly recruit TrkB to the plasma membrane of CNS neurons. Neuron 21:681-693.

Miller S, Yasuda M, Coats JK, Jones Y, Martone ME, Mayford M (2002) Disruption of dendritic translation of CaMKII $\alpha$ impairs stabilization of synaptic plasticity and memory consolidation. Neuron 36:507-519.

Minichiello L, Calella AM, Medina DL, Bonhoeffer T, Klein R, Korte M (2002) Mechanism of TrkB-mediated hippocampal long-term potentiation. Neuron 36:121-137.

Moita MA, Lamprecht R, Nader K, LeDoux JE (2002) A-kinase anchoring proteins in amygdala are involved in auditory fear memory. Nat Neurosci 5:837-838.

Montarolo PG, Goelet P, Castellucci VF, Morgan J, Kandel ER, Schacher S (1986) A critical period for macromolecular synthesis in long-term heterosynaptic facilitation in Aplysia. Science 234:1249-1254.

Muller U, Carew TJ (1998) Serotonin induces temporally and mechanistically distinct phases of persistent PKA activity in Aplysia sensory neurons. Neuron 21:1423-1434.

Murray B, Alessandriui A, Cole AJ, Furshpan EJ (1998) Inhibition of the p42/44 MAP kinase pathway protects hippocampal neurons in a cellculture model of seizure activity. Proc Natl Acad Sci USA 95:11975-11980.

Nguyen PV, Woo NH (2003) Regulation of hippocampal synaptic plasticity by cyclic AMP-dependent protein kinases. Prog Neurobiol 71:401-437.

Opazo P, Watabe AM, Grant SG, O'Dell TJ (2003) Phosphatidylinositol 3-kinase regulates the induction of long-term potentiation through extracellular signal-related kinase-independent mechanisms. J Neurosci 23:3679-3688.

Ormond J, Hislop J, Zhao Y, Webb N, Vaillaincourt F, Dyer JR, Ferraro G, Barker P, Martin KC, Sossin WS (2004) ApTrkl, a Trk-like receptor, mediates serotonin-dependent ERK activation and long-term facilitation in Aplysia sensory neurons. Neuron 44:715-728.

Pang PT, Teng HK, Zaitsev E, Woo NT, Sakata K, Zhen S, Teng KK, Yung WH, Hempstead BL, Lu B (2004) Cleavage of proBDNF by tPA/plasmin is essential for long-term hippocampal plasticity. Science 306:487-491.

Patterson SL, Pittenger C, Morozov A, Martin KC, Scanlin H, Drake C, Kandel ER (2001) Some forms of cAMP-mediated long-lasting potentiation are associated with release of BDNF and nuclear translocation of phospho-MAP kinase. Neuron 32:123-140.

Pepio AM, Thibault GL, Sossin WS (2002) Phosphoinositide-dependent kinase phosphorylation of protein kinase C Apl II increases during intermediate facilitation in Aplysia. J Biol Chem 277:37116-37123.

Purcell AL, Sharma SK, Bagnall MW, Sutton MA, Carew TJ (2003) Activation of a tyrosine kinase-MAPK cascade enhances the induction of longterm synaptic facilitation and long-term memory in Aplysia. Neuron 37:473-484.

Roberson ED, English JD, Adams JP, Selcher JC, Kondratick C, Sweatt JD (1999) The mitogen-activated protein kinase cascade couples PKA and PKC to cAMP response element-binding protein phosphorylation in area CA1 of hippocampus. J Neurosci 19:4337-4348.

Sacktor TC, Schwartz JH (1990) Sensitizing stimuli cause translocation of protein kinase C in Aplysia sensory neurons. Proc Natl Acad Sci USA 87:2036-2039.

Sacktor TC, Osten P, Valsamis H, Jiang X, Naik MU, Sublette E (1993) Persistent activation of the $\zeta$ isoform of protein kinase $\mathrm{C}$ in the maintenance of long-term potentiation. Proc Natl Acad Sci USA 90:8342-8346.

Santarelli L, Montarolo P, Schacher S (1996) Neuropeptide localization in varicosities of Aplysia sensory neurons is regulated by target and neuro- modulators evoking long-term synaptic plasticity. J Neurobiol 31:297-308.

Schacher S, Castellucci VF, Kandel ER (1988) cAMP evokes long-term facilitation in Aplysia sensory neurons that requires new protein synthesis. Science 240:1667-1669.

Schacher S, Kandel ER, Montarolo P (1993) cAMP and arachidonic acid simulate long-term structural and functional changes produced by neurotransmitters in Aplysia sensory neurons. Neuron 10:1079-1088.

Schacher S, Wu F, Panyko JD, Sun ZY, Wang D (1999) Expression and branch-specific export of mRNA are regulated by synapse formation and interaction with specific postsynaptic targets. J Neurosci 19:6338-6347.

Schafe GE, LeDoux JE (2000) Memory consolidation of auditory pavlovian fear conditioning requires protein synthesis and protein kinase $\mathrm{A}$ in the amygdala. J Neurosci 20:RC96(1-5).

Schratt GM, Nigh EA, Chen WG, Hu L, Greenberg ME (2004) BDNF regulates the translation of a select group of mRNAs by a mammalian target of rapamycin-phosphatidylinositol 3-kinase-dependent pathway during neuronal development. J Neurosci 24:7366-7377.

Scott R, Bourtchuladze R, Gossweiler S, Dubnau J, Tully T (2002) CREB and the discovery of cognitive enhancers. J Mol Neurosci 19:171-177.

Sherff CM, Carew TJ (1999) Coincident induction of long-term facilitation in Aplysia: cooperativity between cell bodies and remote synapses. Science 285:1911-1914.

Si K, Giustetto M, Etkin A, Hsu R, Janisiewicz AM, Miniaci MC, Kim JH, Zhu H, Kandel ER (2003) A neuronal isoform of CPEB regulates local protein synthesis and stabilizes synapse-specific long-term facilitation in Aplysia. Cell 115:894-904.

Smith WB, Starck SR, Roberts RW, Schuman EM (2005) Dopaminergic stimulation of local protein synthesis enhances surface expression of GluR1 and synaptic transmission in hippocampal neurons. Neuron 45:765-779.

Sossin WS, Schwartz JH (1992) Selective activation of $\mathrm{Ca}^{2+}$-activated PKCs in Aplysia neurons by 5-HT. J Neurosci 12:1160-1168.

Steward O, Worley P (2002) Local synthesis of proteins at synaptic sites on dendrites: role in synaptic plasticity and memory consolidation? Neurobiol Learn Mem 78:508-527.

Sutton MA, Carew TJ (2000) Parallel molecular pathways mediate expression of distinct forms of intermediate-term facilitation at tail sensory neuron synapses in Aplysia. Neuron 26:219-231.

Sutton MA, Bagnall MW, Sharma SK, Shobe J, Carew TJ (2004) Intermediate-term memory for site-specific sensitization in Aplysia is maintained by persistent activation of protein kinase C. J Neurosci 24:3600-3609.

Sweatt JD (2004) Mitogen-activated protein kinases in synaptic plasticity and memory. Curr Opin Neurobiol 14:311-317.

Takei N, Inamura N, Kawamura M, Namba H, Hara K, Yonezawa K, Nawa H (2004) Brain-derived neurotrophic factor induces mammalian target of rapamycin-dependent local activation of translation machinery and protein synthesis in neuronal dendrites. J Neurosci 24:9760-9769.

Tang SJ, Reis G, Kang H, Gingras AC, Sonenberg N, Schuman EM (2002) A rapamycin-sensitive signaling pathway contributes to long-term synaptic plasticity in the hippocampus. Proc Natl Acad Sci USA 99:467-472.

Udo H, Jin I, Kim JH, Li HL, Youn T, Hawkins RD, Kandel ER, Bailey CH (2005) Serotonin-induced regulation of the actin network for learningrelated synaptic growth requires Cdc42, N-WASP, and PAK in Aplysia sensory neurons. Neuron 45:887-901.

Waltereit R, Weller M (2003) Signaling from cAMP/PKA to MAPK and synaptic plasticity. Mol Neurobiol 27:99-106.

Wu F, Friedman L, Schacher S (1995) Transient versus persistent functional and structural changes associated with facilitation of Aplysia sensorimotor synapses are second messenger-dependent. J Neurosci 15:7517-7527.

Yamamoto N, Hegde AN, Chain DG, Schwartz JH (1999) Activation and degradation of the transcription factor C/EBP during long-term facilitation in Aplysia. J Neurochem 73:2415-2423.

Yanow SK, Manseau F, Hislop J, Castellucci VF, Sossin WS (1998) Biochemical pathways by which serotonin regulates translation in the nervous system of Aplysia. J Neurochem 70:572-583. 